\title{
La dimensión Jurídica del Estado de Cosas Inconstitucional en el caso de las víctimas del desplazamiento forzado en Colombia*
}

\author{
The legal dimension of the Unconstitutional State of Affairs in \\ the case of the victims of forced displacement in Colombia
}

\author{
Sonia Patricia Cortés Zambrano** \\ Universidad Santo Tomás. Villavicencio. Colombia \\ soniacortes@usantotomas.edu.co
}

\section{RESUMEN}

Se realiza un análisis del desplazamiento forzado como realidad del Estado colombiano como consecuencia del problema de la tierra, poniendo de manifiesto la precariedad del ejercicio del poder en cuanto al cumplimiento de los fines del Estado y la materialización o realización efectiva de los DDHH en Colombia. A su vez, se analiza la manera en la que el rol de la Corte Constitucional -en sus declaraciones de Estado de Cosas Inconstitucional-, hace visible el problema de las víctimas de desplazamiento forzado que superan los 59, 5 millones de desplazados (8, 3 millones más que en 2013, lo que equivale a la población de Italia o del Reino Unido), siendo Colombia el segundo drama humanitario más grande del mundo. Para finalizar, el documento examina la forma en que el poder vinculante de la Constitución tiene como norte la protección efectiva de derechos fundamentales y derechos humanos en Colombia.

Palabras clave: Víctimas, Desplazamiento forzado, Tierras, Justicia constitucional, Derechos Humanos, Estado de cosas inconstitucional, Neoconstitucionalismo, Estado Social.

Fecha de recepción: 26 de agosto de 2016

Fecha de aceptación: 29 de septiembre de 2016

Como citar este artículo: Cortés Zambrano, S. (julio-diciembre, 2016). "La dimensión jurídica del Estado de Cosas Inconstitucional en el caso de las víctimas del desplazamiento forzado en Colombia". Revista Diálogos de Saberes, (45). Universidad Libre (Bogotá).

* Este artículo es producto de investigación del proyecto El desplazamiento forzado, un Estado de Cosas Inconstitucional vigente en Colombia". Proyecto convocatoria interna de la Universidad Santo Tomás, sede Villavicencio.

** Abogada Universidad Santo Tomás, Especialista en Derecho Constitucional y Derecho Parlamentario de las Universidades Externado de Colombia y Autónoma de Madrid, España. Magister en Derecho Público de las Universidades Santo Tomás y Universidad de Konstanz Alemania, Candidata a Doctora en Derecho de la Universidad Externado de Colombia, Docente Investigadora, Decana de la Facultad de Derecho Universidad Santo Tomás, sede Villavicencio, y Consultora en Planificación y Gobierno, Diseño y Gestión de Políticas Públicas, Planeación y Gestión Estratégica para el Desarrollo en el marco de los Derechos Humanos. 


\begin{abstract}
An analysis of forced displacement as a reality of the Colombian State, and as a consequence of the land problem, revealing the precariousness of the exercise of power, as regards the fulfillment of the State's goals and the materialization or effective realization of Human Rights in Colombia, and how the role of the Constitutional Court in its declarations of unconstitutional state of affairs makes visible the problem of victims of forced displacement, which exceed 59.5 million displaced persons (8. 3 million more than in 2013, Which is equivalent to the population of Italy or the United Kingdom), with Colombia being the second largest humanitarian drama in the world, and how the binding power of the Constitution is based on the effective protection of fundamental rights and human rights in Colombia.
\end{abstract}

Key words: Victims, Forced Displacement, Lands, Constitutional Justice, Human rights, Unconstitutional State of Affairs, Neo-constitutionalism, Social State.

\section{INTRODUCCIÓN}

Colombia, como Estado constitucional, estructura sus fines dentro de los parámetros de justicia, igualdad, libertad y paz, en el marco de un ordenamiento jurídico constitucional democrático y participativo que busca garantizar el orden político, económico y social del país. Se consideran, desde una perspectiva crítica, algunos temas a través de los cuales se valora el cumplimiento de los postulados constitucionales enmarcados como fines del Estado.

La Constitución Política de Colombia ya no es solo una fórmula de reparto de poderes, sino que comprende la institucionalización de unos valores como principios, disposiciones y derechos fundamentales. Por otro lado, ella está garantizada materialmente y es exigible jurídicamente no solo a través de la Corte Constitucional, sino también a través de los jueces ordinarios que se convierten en jueces constitucionales en vía de tutela.

Schmitt (1983), presagiaba ya que la jurisdicción constitucional llevaría, sin duda, al gobierno de los jueces, y se ha podido constatar en nuestro país la judicialización de la política, decisiones políticas que emanan de la Corte Constitucional y que se adoptan desde el cumplimiento de los postulados de la Constitución colombiana, postulados que, sin embargo, el propio Estado no puede cubrir, generándose el llamado activismo judicial.

Pese a los innegables procesos de evolución constitucional plasmados en el modelo de Estado constitucional, se evidencia que el proceso evolutivo continúa y que la tutela constituye el instrumento de mayor efectividad en la protección de derechos fundamentales en Colombia. Sin embargo, en esta reflexión se juzgará el rol de la Corte Constitucional y del Estado a la hora de administrar la justicia, concretamente frente al flagelo de desplazamiento forzado.

Con el poder que ostenta la Corte Constitucional se ha puesto en tela de juicio el principio de seguridad jurídica que encuentra sustento en conceptos como el de cosa juzgada, sentencia en firme, certeza del derecho e interpretación uniforme, pero ante la cual, tal y como lo señala 
Hart (1961, p. 99), la existencia de una única respuesta correcta que excluye la posibilidad de discreción judicial es un "noble sueño". Frente al tema, López (2000, p. 42), advierte que luego de más de 25 años de sentencias constitucionales, debe tenerse en cuenta la importancia del precedente constitucional, así como revalorar la actividad del juez constitucional a partir del estudio de la jurisprudencia constitucional como fuente de derecho, lo cual constituye una vía que refuerza el rol de la justicia constitucional y fundamenta la constitucionalizarían del derecho.

Sin embargo, no debe olvidarse que la independencia judicial es un principio axial del Estado de Derecho que se funda, a su vez, en los principios de libre interpretación de la ley por parte del juez y su capacidad de valorar de manera libre el material probatorio. El proceso decisional de los jueces ocasionalmente puede convertirse, por otro lado, en ropaje de la arbitrariedad o sinrazón, si lo separamos del ejercicio racional de la justa ponderación. Algunos atacan el proceso evolutivo hacia el neoconstitucionalismo basados en que el derecho está llamado, precisamente, a generar certidumbre y seguridad jurídica. Esta postura radical no es práctica, la visión positiva de esta evolución obedece a que los cambios son naturales y la ciencia jurídica debe adaptarse a ellos y a las realidades constitucionales.

El nuevo rol de la Corte Constitucional en Colombia, y en varios países de Occidente, sin duda ha generado una problemática en cuanto a la separación de los poderes, ya que "no solo aplican derecho a un caso concreto, como ordinario corresponde al juzgador. En realidad, las cortes constitucionales, con ocasión del control de constitucionalidad, también crean derecho, que obliga incluso al legislador" (Morelli, 1997, p. 11). De esta manera podemos ver que existe interacción entre la Corte y el legislador en cuanto a decisiones políticas y jurisdiccionales.

De la actividad de la Corte Constitucional se deriva, así, el llamado activismo constitucional, generado a su vez por la doble vinculación de los jueces a la ley y a la Constitución. Por lo tanto, los jueces imparten justicia aplicando el derecho vigente desde la perspectiva moderna, propia de un Estado Constitucional de derecho que supone su doble sumisión a la Constitución y a la ley.

Por otra parte, con respecto a las relaciones entre el gobierno y los jueces, el tema de tridivisión de poderes y su importancia en la concreción del funcionamiento de cualquier Estado, se da a partir del respeto por las funciones y de una colaboración entre ellas para la consecución de los fines propios del Estado, y frente al problema de la efectividad de los derechos se presenta la suplantación de las funciones del gobierno por parte de los órganos judiciales.

Ante la ineficiencia política del Congreso y del Ejecutivo (que genera vacíos de poder y pone en tela de juicio la garantía de los derechos fundamentales y la materialización de los DDHH), se establece el Estado de Cosas Inconstitucional. Este reclama de la Corte una rápida y efectiva intervención, dando lugar a decisiones jurisprudenciales que pueden llegar a tener lineamientos importantes con tintes de orden político y que dan origen a ideas de usurpación de funciones entre las ramas del poder público y a la vulneración del principio constitucional de separación de poderes. 
El Estado tiene funciones separadas de estabilidad, orden y garantías para que los ciudadanos ejerzan en paz sus derechos y deberes. Esto implica la existencia de un derecho, preciso, estable y permanente, orientador de un espacio de convivencia armónica (Medina, 2009, p. 162) y de logros reconocibles en hechos. De ahí que el derecho como ciencia social normativa tenga por propósito el proteger a las poblaciones más débiles, promover un espacio de convivencia pacífica y civilizada, restringir el uso de la fuerza y garantizar las condiciones mínimas de vida.

\section{PODER DISCRECIONAL DE LA CORTE CONSTITUCIONAL EN EL ESTADO DE COSAS INCONSTITUCIONAL}

Cada vez es más extraño oír hablar de "legalidad constitucional", de "leyes contrarias al principio de legalidad", de "leyes ilegales", o incluso de "legalidad constitucional, legislativa y reglamentaria" (Moreso, 2003, p. 99). Hoy en día se usa la noción de constitucionalidad, llegando en algunos casos incluso a reemplazar la noción de legalidad.

En el Estado de Derecho la legalidad es un componente de la constitucionalidad que adopta un papel distinto del que tenía en el Estado de legalidad. La legalidad fue reemplazada por la constitucionalidad por lo menos en dos funciones: al ser fuente de fuentes y vehículo de valores esenciales o fundamentales (Moreso, 2003, p. 102)

La Constitución irradia todo el ordenamiento jurídico y este, a su vez, debe ser interpretado a partir de las disposiciones, los valores y los principios constitucionales, que imponen la ponderación como herramienta fundamental del juez constitucional. En ese orden de ideas, al juez constitucional le está permitido establecer prioridades en procura del resguardo de la Constitución y la protección de los derechos fundamentales, y más aún cuando tal vulneración se deriva de una actividad propia del Estado.

La Corte Constitucional, a través de desarrollo jurisprudencial, creó un término denominado "Estado de Cosas Inconstitucional" que es consecuencia de la ausencia del Estado, entendida como vulneración efectiva a derechos fundamentales a partir de la inoperancia del mismo. Es allí donde el poder discrecional de la Corte Constitucional entra a tomar decisiones administrativas y políticas por fuera del marco de su competencia, aplicando la nueva interpretación constitucional. A continuación se describen los casos.

\subsection{Estado de Cosas Inconstitucional}

La Corte Constitucional ha desarrollado, desde 1997, el concepto de Estado de Cosas Inconstitucional con la Sentencia SU-559 de 1997, que consistió en el tratamiento de un estado de cosas contrario a la Constitución Política en temas como la distribución del situado fiscal en materia educativa y en la afiliación de los docentes de las entidades territoriales al Fondo Nacional de Prestaciones Sociales del Magisterio. En ese año se dio a conocer dicha figura por primera vez en nuestro país. Posteriormente, en la Sentencia T-025 de 2004, se establece dicha noción cuando se comprueba que existe una repetida vulneración de derechos fundamentales a un número significativo de personas, que pueden 
recurrir a la acción de tutela para obtener defensa de sus derechos, no solo frente a una entidad demandada sino a factores estructurales del Estado.

Es decir, si existe una vulneración repetida a los derechos fundamentales, que afecta a un sinnúmero de personas y cuya solución requiere la intervención de distintas entidades para atender problemas estructurales, y la Corte Constitucional así lo estima probado, declarará la existencia de un Estado de Cosas Inconstitucionales con el objetivo de ordenar mejoras para las personas que han interpuesto acciones de tutela (y las que no lo han ejercido pero están inmersas en la misma situación), para lograr la protección de sus derechos fundamentales.

La Corte Constitucional en Sentencia T-025 de 2004, falla la acumulación de 109 procesos de tutela, interpuestas por 1150 núcleos familiares, todos pertenecientes a la población desplazada, con un promedio de cuatro personas por núcleo y compuesta principalmente por mujeres cabeza de familia, niños, personas de la tercera edad así como algunos indígenas. Los accionantes se encuentran ubicados principalmente en las ciudades capitales y municipios: Armenia, Calarcá, Cali, Florencia, Girón, Ibagué, Itagüí, Medellín, Neiva, Obando, Pasto, Pereira, Piedecuesta, Popayán, Riohacha, Taminango, y Villavicencio.

La vulneración de los derechos fundamentales, en buena parte, se debe a condiciones de sobrepoblación que fomentan el desempleo, la crisis de la institución de la familia, la precariedad en la educación, la alimentación y la salud, etc. (Cifuentes, 1998), es decir, es evidente la falla en el cumplimiento de los fines del Estado por parte del gobierno y para el caso especial de los desplazados, la Corte Constitucional concluye que por las condiciones de vulnerabilidad extrema de las víctimas de desplazamiento forzado, así como por la omisión reiterada de brindarle protección oportuna y efectiva por parte de las distintas autoridades encargadas de su atención, se han violado los derechos a una vida digna, integridad personal, a la igualdad, de petición, al trabajo, a la salud a la seguridad social, a la educación, al mínimo vital y a la protección especial debida a las personas de la tercera edad, a la mujer cabeza de familia y a los niños.

Los derechos fundamentales, estipulados en la Constitución Política, constituyen precisamente una limitación al principio de las mayorías, con el mínimo de garantizar los derechos de las minorías y de los individuos en condiciones de debilidad o vulnerabilidad. En otras palabras, el juez constitucional está obligado a tomar la vocería de las minorías, grupos olvidados y grupos que presentan dificultad al acceder a organismos políticos.

Es por ello que cuando se presenta el Estado de Cosas Inconstitucional, la Corte Constitucional actúa para evitar la vulneración de derechos fundamentales generados a partir de la omisión o la actuación ineficiente del Estado, exigiendo la toma de medidas oportunas y eficaces por parte de las distintas ramas del poder y sus órganos, para la atención y solución inmediata con miras al cese de la amenaza o vulneración.

Tal vulneración de derechos no es imputable a una sola entidad, sino que todas las 
autoridades nacionales y territoriales con responsabilidades diversas en la atención de la población desplazada, por acción u omisión, han permitido que continúe y en algunos casos se agrave la vulneración de los derechos fundamentales de la comunidad desplazada.

La Corte Constitucional dispone que el Consejo Nacional para la atención integral a la población desplazada por la violencia, "asegure la coherencia entre las obligaciones fijadas por las autoridades competentes y el volumen de los recursos efectivamente destinados a proteger los derechos de los desplazados y redefinir los compromisos después de ofrecer oportunidades suficientes de participación a los representantes de los desplazados, de manera que sus prioridades sean realmente atendidas y a todos y cada uno de los desplazados se les asegure el goce efectivo de sus derechos mínimos" (Corte Constitucional, Sentencia T-025 /2004).

\subsection{Gravedad del fenómeno de desplazamiento en Colombia}

La Corte Constitucional ha calificado el desplazamiento forzado un problema de humanidad, que debe ser afrontado solidariamente por todas las personas, comenzando por el Estado (Corte Constitucional, Sentencia T-227/1997), se ha identificado por instituciones gubernamentales y no gubernamentales como una emergencia social y tragedia social humanitaria, y un Estado de Cosas Inconstitucional, que contraría los pilares del Estado Social y el carácter constitucional del Estado colombiano, ya que se considera un hecho abiertamente contrario a los principios y valores constitucionales que rigen la actividad del Estado.
Los derechos vulnerados con esta crisis, son: derecho a la vida en condiciones de dignidad; los derechos de los niños, mujeres cabeza de familia y personas de la tercera edad; derecho a escoger lugar de domicilio; derecho al libre desarrollo de la personalidad; derechos sociales, económicos y culturales; derecho a la unidad familiar, a la salud, a la integridad personal, a la seguridad personal, a la libertad de circulación en el territorio nacional; derecho al trabajo; derecho a la alimentación; derecho a la educación; derecho a una vivienda digna; derecho a la paz; derecho a la personalidad jurídica; y derecho a la igualdad.

Tal vulneración se evidencia dadas las circunstancias infrahumanas asociadas a su movilización y su permanencia en el lugar de llegada, las precarias condiciones que deben afrontar quienes son obligados a desplazarse, el peligro que corren sus vidas y su integridad personal, el ambiente intimidatorio que precede y el que acompaña el periodo de desplazamiento y su permanencia en lugares que no son su hogar, su sitio habitual de residencia y trabajo, los altísimos niveles de pobreza extrema a los que llegan numerosas personas desplazadas, que impide satisfacer sus necesidades más esenciales, la dificultad que tienen un gran número de personas para registrarse como desplazados a acceder a las ayudas y sufren de discriminación por su condición.

Según Naciones Unidas (ONU, 2014), el 95\% de la población desplazada presenta necesidades básicas insatisfechas y el $92 \%$ se encuentra en situación de indigencia, el 43\% de los niños y niñas menores de 6 años desplazados están por debajo del estándar alimenticio mínimo, 
el $25 \%$ de los niños entre 6 y 9 años no asisten al colegio y la tasa de mortalidad para la generalidad de la población desplazada es 6 veces superior al promedio nacional.

La Ley 387 de 1997, establece que:

\begin{abstract}
"Es desplazada toda persona que se ha visto forzada a migrar dentro del territorio nacional, abandonando su localidad de residencia o sus actividades económicas habituales, porque su vida, su integridad física, su seguridad o libertad personales han sido vulneradas o se encuentran directamente amenazadas, con ocasión de cualquiera de las siguientes situaciones: conflicto armado interno, disturbios, tensiones interiores, violencia generalizada, violaciones masivas de los Derechos Humanos, infracciones al Derecho Internacional humanitario $u$ otras circunstancias emanadas de las situaciones anteriores que puedan alterar el orden público".
\end{abstract}

Pese a que las políticas públicas de atención a los desplazados en Colombia se han implementado, los resultados no han contrarrestado la situación de vulneración de derechos fundamentales y ello se explica en los problemas de capacidad institucional de protección a los desplazados: no existe plan de acción estratégico, no hay metas específicas y determinación concreta de actividades y las funciones y responsabilidades son difusas, lo cual impide un seguimiento eficaz a la gestión y por otra parte, la insuficiencia en la apropiación de recursos para la implementación de políticas de atención a la población desplazada, que consiste en la escasez de recursos, incumplimiento de las entidades nacionales y territoriales con sus deberes constitucionales, de asegurar la suficiente apropiación presupuestal.

\subsection{El problema de la tierra en Colombia}

Colombia, pese a su riqueza en recursos naturales, sus 4.2 millones de hectáreas cultivables, su riqueza hídrica, dos mil novecientos kilómetros de costa sobre los dos océanos, importante riqueza minero energética, el 50\% de los páramos del mundo están en Colombia, y es el segundo país del planeta en biodiversidad, posición geográfica más estratégica del continente, padece un importante y único problema que constituye el gran freno al desarrollo económico y social.

Podría empezar por señalar que de los 4.2 millones de hectáreas de tierras solo el $20 \%$ es decir el 8.5 millones de hectáreas son para producción agropecuaria y el $80 \%$ es decir 33.8 millones de hectáreas de tierra son destinadas a pastoreo de ganado (las vacas de Colombia son las mejor alimentadas del mundo tienen una hectárea y media para cada una, en Holanda agrupan 140 vacas por hectárea). De las hectáreas cultivables, 7.1 millones de ellas son destinadas para productos de exportación (café, palma, azúcar) y 1.4 millones son para cultivo de productos para el consumo interno (IGAC, 2015).

Lo anterior significa que cinco millones de pequeños campesinos producen el $43 \%$ de los alimentos que se consumen en Colombia. Esto unido a que el $0.4 \%$ de la población del país posee el $46 \%$ de la tierra, según el censo agropecuario. Las víctimas: los campesinos, cinco millones de personas que viven en condiciones de pobreza y con un $15 \%$ de ciudadanos analfabetas; en el campo el 83\% de los niños y 
niñas no son escolarizados, el $80 \%$ no termina la secundaria y solo el $1 \%$ va a la universidad (DANE, 2016).

En cuanto los servicios públicos el panorama sigue igual de desalentador, el $60 \%$ de los campesinos de Colombia no tienen agua, y el $85 \%$ no tiene alcantarillado, el $65 \%$ de los campesinos nunca ha recibido asistencia técnica, ni maquinaria, ni ayudas económicas para potencializar la actividad agrícola y el acceso a la salud es precario tanto más que en la ciudades.

Es en este campo donde se vive la guerra, dejando más de seis millones de desplazados que han emigrado a las ciudades por la presión de la guerrilla, el paramilitarismo y su confrontación con el ejército (Centro de Memoria Histórica, 2016). Es en el campo donde operan las grandes empresas explotadoras de la riqueza minero-energética, con las consecuencias medioambientales ya conocidas, ensuciando el agua, perforando la tierra y desplazando a los campesinos, fumigando cultivos ilícitos y lícitos.

Por otro lado, está el impacto al ciudadano. Colombia importa a empresas del exterior diez millones de toneladas de alimentos cada año (el 99\% de los cereales que se consumen, el 80\% del maíz, el 50\% del arroz y más del 50\% del frijol, arveja y lenteja. Colombia importa arroz de Estados Unidos, Filipinas y Ecuador, el maíz viene de Estados Unidos, Canadá y Argentina, y el frijol viene de Canadá; importa además carne de Estados Unidos y Argentina; los huevos son importados de Alemania y el plátano de Ecuador). Los colombianos compran comida cara porque esta viene del exterior y está sujeta al precio del dólar. Por esto el problema de la tierra frena el desarrollo económico y social en Colombia, generando la pobreza y el conflicto armado interno.

Así las cosas, el primer problema para abordar el tema de víctimas de desplazamiento forzado en Colombia es el desarrollo agrario. Los acuerdos de La Habana, que impulsan el proceso de paz en Colombia (2016) ratificados por el Gobierno nacional tratan la problemática así:

Primero: Crear un fondo de tierras y distribuirlas para que más campesinos puedan ser propietarios. Las tierras salen de lotes baldíos, tierras expropiadas por extinción de dominio, y tierras que hacen parte de algunas reservas forestales, que perdieron su valor de reserva. Unas se entregarán en forma gratuita y otras a través de créditos y subsidios, generando con ello solución a uno de los problemas de tierras más antiguos de Colombia, claridad sobre los propietarios y las propiedades. Se crearán organismos especiales para formalizar la propiedad.

Segundo: Implementación de programas de desarrollo rural, se destinaran recursos para capacitaciones, brigadas de atención integral, préstamos, todo con la participación de las comunidades.

Tercero: Transformar la infraestructura nacional, para combatir la desigualdad entre el campo y la ciudad, construyendo vías y redes eléctricas, para aprovechar las tecnologías de comunicación, abrir centros de salud y escuelas, llevar agua potable, etc:, es decir, ahora sí se usarán los recursos para lo que son. 


\subsection{El estatus de víctima de los desplazados en Colombia}

Las víctimas de desplazamiento hacen parte de la población más vulnerable y es un deber internacional de Estado diseñar medidas para que las víctimas de violación a Derechos Humanos superen su condición de vulnerabilidad. Se crean en Colombia mecanismo se instrumentos institucionales y legislativos de política masiva de reparaciones, que posibiliten la reglamentación y la organización institucional para garantizar a las víctimas, medidas de asistencia, de ayuda humanitaria y garantías judiciales en los procesos penales que cursan contra sus victimarios ${ }^{1}$, una situación de prioridad nacional.

El Estado parte del reconocimiento de la condición de víctimas, del reconocimiento de las responsabilidades por parte de los agresores, satisfacción de los derechos de las víctimas, participación de las víctimas en los acuerdos, esclarecimiento de la verdad, reparación de las víctimas, garantías de protección y seguridad, garantía de no repetición, principio de reconciliación y enfoque diferencial de derechos.

Ley 387 de 1997, por la cual se adoptan medidas para la prevención del desplazamiento forzado; la atención, protección (...) socioeconómica de los desplazados internos por la violencia en la República de Colombia.

Ley 1448 de 2011, Ley de Víctimas y Restitución de Tierras. Por la cual se dictan medidas de atención, asistencia y reparación integral a las víctimas del conflicto.

Acto Legislativo 01 de 2012, Marco Jurídico para la Paz, por medio del cual se establecen instrumentos jurídicos de justicia transicional en el marco del artículo 22 sobre la terminación del conflicto armado interno y el logro de la paz estable y duradera.
La gravedad y magnitud del problema del desplazamiento en Colombia, generó lo que la Corte denominó Estado de Cosas Inconstitucional, es un concepto de creación jurisprudencial que se configura cuando se constata una vulneración masiva, repetida y constante de derechos fundamentales, que afectan a una multitud de personas y cuya solución requiere la intervención de distintas entidades para atender problemas de orden estructural.

\subsection{Presupuestos que determinan el Estado de Cosas Inconstitucional}

La Misión Internacional determinó las condiciones para que se configure el "Estado de Cosas Inconstitucional" con los siguientes supuestos:

a. Patrón de violaciones graves y sistemáticas: Se observó la existencia de un patrón de violaciones graves, sistemáticas y generalizadas de las obligaciones del Estado Colombiano con respecto a los derechos humanos en los establecimientos carcelarios, pues el maltrato por parte de las autoridades judiciales, policiales y penitenciarias hacia las personas en detención claramente constituye una violación a los derechos fundamentales de las personas.

b. Ingobernabilidad y violencia: Se constató la falta de capacidad de gestión de los limitados recursos financieros, logísticos y humanos disponibles. A esto se le suma la impresionante corrupción e impunidad del sistema carcelario.

c. Incumplimiento de obligaciones: El Estado colombiano no se compromete seriamente a proteger la vida, la integridad física, 
la dignidad ni la seguridad jurídica de las personas, y menos aún de los que se encuentran privados de la libertad, situación que lleva a que no existe seguridad humana de la población general del país.

d. Responsabilidades: La Misión observó que el Estado colombiano, a través de sus instituciones responsables, no ha adoptado medidas efectivas para resolver las situaciones, ni tampoco ha realizado la debida aplicación de las leyes vigentes y las normativas en cuanto a Derechos Humanos se trata.

e. Las autoridades colombianas: Constituye un ejercicio de relaciones públicas que esconde la verdadera crisis de los Derechos Humanos y Fundamentales, pues las instituciones responsables minimizan la situación y realizan manipulaciones de estadísticas.

f. Política Criminal: Existen, evidentemente, problemas sociales y políticos que no se encaran debidamente. Esto da lugar a la sobre-criminalización de conductas, de contravenciones, incremento de penas, aumento de delitos no excarcelables y el agravamiento de penas. Comportamientos que deben ser de un control social, donde el Estado colombiano no realiza visitas e incumple con su obligación legal de verificar las condiciones de las penas.

La Corte Constitucional ha estipulado los siguientes factores: a) vulneración masiva y generalizada de varios derechos constitucionales que afecta a un número significativo de personas; b) prolongada omisión de las autoridades en el cumplimiento de sus obligaciones para garantizar los derechos; c) adopción de prácticas como la acción de tutela como parte del procedimiento para garantizar el derecho conculcado; d) no expedición de medidas legislativas, administrativas o presupuestales necesarias para evitar la vulneración de los derechos; e) existencia de un problema social cuya solución compromete la intervención de varias entidades, elemento que requiere la adopción de un conjunto complejo y coordinado de acciones que exige, a su vez, un nivel de recursos que demanda un importante esfuerzo presupuestal adicional; y f) si todas las personas afectadas por el mismo problema acudieran a la acción de tutela para obtener la protección de sus derechos, se produciría una mayor congestión judicial (Cortés, 2012).

La Corte Constitucional declara formalmente la existencia de un Estado de Cosas Inconstitucional relativo a las condiciones de vida de la población desplazada y adopta los remedios judiciales correspondientes respetando la órbita competencia y la experticia de las autoridades responsables de implementar las políticas correspondientes y ejecutar las leyes pertinentes. Por ello, tanto las autoridades nacionales como territoriales, deben adoptar las decisiones que conlleven a superar el estado de cosas inconstitucional.

Ha ordenado la Corte Constitucional que se diseñen políticas, planes o programas que garanticen de manera adecuada los derechos fundamentales, la apropiación de los recursos necesarios para garantizar la efectividad de dichos derechos, la modificación de las fallas de organización y de procedimiento que sean violatorias a la Constitución Política, la modificación del marco jurídico cuyas falencias han ayudado al Estado de Cosas 
Inconstitucionales y, por último, la realización de los trámites administrativos, presupuestales y de contratación que sean indispensables para superar la vulneración de los derechos fundamentales.

\section{PRESUPUESTOS DE ESTADO DE COSAS INCONSTITUCIONAL EN EL CASO DE LAS VÍCTIMAS DEL DESPLAZAMIENTO FORZADO}

\subsection{La vulneración masiva y generalizada de varios derechos constitucionales que afecta a un número significativo de personas}

Esta vulneración consiste en la amenaza o violación de los derechos estipulados en la Constitución Política a un gran número de personas. Así, por ejemplo: el derecho a la vida, a la integridad física, a la seguridad o a la libertad personal, a la alimentación, a la salud, y los derechos de los niños, entre otros.

Según la Sentencia SU-559 de 1997, "si el Estado de Cosas que como tal no se compadece con la Constitución Política, tiene relación directa con la violación de los derechos fundamentales", es decir, al recibir una acción de tutela, la Corte Constitucional debe verificar y realizar la debida notificación de la irregularidad existente. Esta podrá acompañarse, igualmente, de un requerimiento específico dirigido a las autoridades para que realicen acciones y omisiones sobre el caso.

Esto conforma una serie de órdenes que libra la Corte para restablecer el orden fundamental quebrantado, con el propósito de que no exista un obstáculo para los objetivos y planes que formule la Corte Constitucional.
Por otra parte, la Corte Constitucional ha señalado que la administración goza de discrecionalidad para modificar la ubicación territorial de sus funcionarios para que éstos presten un buen servicio. Esta figura se denomina Ius Variandi. Esto con el propósito de que no se vea reflejada una masiva vulneración de derechos fundamentales de los ciudadanos, y se contrarreste con la función de la administración pública en tener posibilidades para trasladar a sus funcionarios de acuerdo con las exigencias del servicio.

Por otro lado, la Sentencia T-025 de 2004 aborda este presupuesto, señalando que dicha vulneración no es imputable a una sola entidad, sino que todas las autoridades nacionales y territoriales con responsabilidades diversas en la atención de una población, por acción u omisión, han permitido que se agrave la vulneración de los derechos fundamentales.

El Estado de Cosas Inconstitucional tiene así, como objeto, que tanto las autoridades nacionales como las territoriales presten un buen servicio a la población y reajusten su actuación de acuerdo con los compromisos adquiridos por los mandatos constitucionales y legales. Todo ello con el propósito de que estos protejan el goce efectivo de los derechos fundamentales.

\subsection{La prolongada omisión de las autoridades en el cumplimiento de sus obligaciones para garantizar los derechos}

Cuando el Estado omite sin justificación constitucionalmente aceptable, tomar medidas frente a la marginación que sufren algunos miembros de la sociedad, la función del juez 
será ordenar el cumplimiento de los deberes del Estado. No el reemplazo en el ejercicio funcional de los órganos del poder público.

Esta omisión, se concreta principalmente, en la insuficiencia de recursos destinados a la atención de los diferentes elementos de la política y los problemas de capacidad institucional que afectan el desarrollo, la implementación y el seguimiento de la política estatal. Constituye un claro ejemplo de la dificultad de las autoridades al adoptar los correctivos necesarios para evitar una condición de vulnerabilidad de las poblaciones, e igualmente, la presencia de obstáculos administrativos que hacen mayor la ineficiencia de las entidades (Caicedo, 2008).

El juez constitucional debe entonces asegurarse de que se alcance el máximo de protección definida por la constitución y la ley con miras a lograr que los desplazados puedan ejercer realmente sus derechos constitucionales.

La Constitución Política, en sus mandatos constitucionales artículo 2 y 209, impone a las autoridades la obligación de atender las necesidades y hacer efectivos los derechos de las personas, así como asegurar el cumplimiento de las obligaciones sociales y los fines del Estado.

\subsection{Adopción de prácticas inconstitucionales, como la incorporación de la acción de tutela como parte del procedimiento para garantizar el derecho conculcado}

La Sentencia T-068 de 1998 refiere, así, que el objeto fundamental de la acción de tutela es la protección inmediata y eficaz de los derechos fundamentales que resulten amenazados o vulnerados, es decir, procurar un amparo que contenga una orden precisa e imperativa concreta en un plazo estipulado.

Sin embargo, si la situación de hecho se ha superado, es decir, si ya no es actual, el juez no puede proferir una orden que proteja derechos fundamentales. Por lo tanto, el fallo no produciría efectos y sería improcedente.

\subsection{La no expedición de medidas legislativas, administrativas o presupuestales necesarias para evitar la vulneración de los derechos fundamentales}

En la Sentencia T-1695 de 2000, la Corte Constitucional advierte que, al estar frente a un derecho fundamental vulnerado, la competencia del juez de tutela no es suficiente para determinar la correspondencia de los mismos con el mandato constitucional y legal, toda vez que el legislador ha creado acciones claras que determinan la concordancia entre un acto determinado y el ordenamiento constitucional y legal, como pueden ser una acción de simple nulidad o la acción de nulidad y restablecimiento del derecho. Acciones ante el Contencioso Administrativo que permiten impugnar ciertos actos que pueden vulnerar derechos fundamentales.

La Corte Constitucional resalta, por otro lado, que para que los derechos sean efectivos dependerán de la eficacia y la eficiencia administrativa. La primera se refiere al cumplimiento de las determinaciones de la administración, y la segunda a la elección de los medios pertinentes para el cumplimiento de los objetivos. Así, pues, se puede deducir que para el cumplimiento de los fines del Estado, 
se requiere que la función administrativa sea eficiente para responder a las obligaciones de un Estado constitucional.

\subsection{La existencia de un problema social cuya solución implica la intervención de varias entidades}

La Sentencia T-068 de 1998 advierte que la legitimidad del Estado Social de Derecho descansa primero en el acceso y ejecución del poder en forma democrática y, segundo, en la capacidad para resolver las dificultades sociales desde la visión de justicia social y el derecho.

Es claro que en Colombia existe una gran cantidad de problemas sociales cuya solución depende de la capacidad del Estado para cumplir, de manera efectiva, sus fines de servicio a la sociedad. También es cierto, sin embargo, que existen problemas de origen político y administrativo, con tintes de corrupción y burocracia que hacen que los intereses que se debaten en la administración sean de orden casi particular más que público o de interés general. Esto hace que el ejercicio del gobierno muchas veces no cumpla su función constitucional y genere vacíos o ausencias que terminan en la vulneración de derechos fundamentales.

La Constitución Política estipula, en sus artículos 2 y 209, la orden a las autoridades en el deber de atender las necesidades básicas de la población. Por lo tanto, las autoridades deben destinar recursos para asegurar el bienestar de las personas y solucionar las necesidades insatisfechas de la población. Esto conlleva que las personas tengan acceso efectivo a los bienes y servicios del Estado.
Por otro lado, es importante anotar que, ante esta problemática, los bienes y servicios deben ser prestados a nivel nacional, sin importar categoría ni grado de desarrollo de municipios o de las regiones. De cualquier modo, lo cierto es que la prioridad es evidente para todas las situaciones y aún más si impera un problema social.

\subsection{Congestión Judicial si todas las personas afectadas por el mismo problema acuden a la acción de tutela}

La Corte Constitucional constata, en la Sentencia T-068 de 1998, que ante una situación de una entidad demandada, que produce un Estado de Cosas Inconstitucional, no sólo se afectan derechos individuales, sino también a todo el aparato jurisdiccional. Es decir que el aparato jurisdiccional se congestiona, y esto afecta a la efectividad del cumplimiento oportuno de sus obligaciones. Ahora bien, si la situación de vulneración de derechos, ya ha sido solucionada, no se puede proferir un fallo, a sabiendas de que éste no producirá ningún efecto y la decisión sería improcedente.

\subsection{Relación entre presupuestos de Ausencia de Estado y Estado de Cosas Inconstitucional}

\section{a. Ausencia de Estado}

La Corte Constitucional plantea dos supuestos de esta figura: el primero, causado por la ausencia de Estado en los territorios; y el segundo, por la presencia del Estado colombiano como antagonista, es decir, cuando el 
Estado juega un papel totalmente opuesto a sus metas de protección.

La ausencia de Estado se entiende como la omisión o el olvido del deber constitucional por parte del Estado hacia sus habitantes, al no cumplir con sus deberes de protección y cubrimiento de sus necesidades fundamentales y dar lugar a la vulneración de derechos constitucionales. El Estado entra, así, en esta categoría al no ser eficiente en el cumplimiento de sus deberes constitucionales frente a las necesidades de la población y el cumplimiento de sus fines: fortalecimiento de la unidad de la nación, asegurar a sus integrantes la vida, la convivencia, el trabajo, la justicia, la igualdad el conocimiento, la libertad, la paz, dentro de un marco jurídico, democrático y participativo, que garantice un orden político, económico y social justo.

Existen diferentes posiciones con respecto a este concepto, ausencia de Estado, en Colombia se interpreta de distintas formas; una de ellas y la más común es la "No presencia del Estado colombiano", que consiste en la no asistencia o manifestación por parte de éste en situaciones que ponen en peligro la integridad de las personas o en presencia de dificultades económicas, políticas y/o culturales. Como presupuestos que determinan la ausencia de Estado tenemos:

Precariedad o carencia de servicios públicos, la Pobreza, como una situación o forma de vida, producto de la imposibilidad de acceso, o carencia de los recursos necesarios, para satisfacer las necesidades básicas físicas y psíquicas de las personas. Ubicación geográfica, problemas de las poblaciones en sus condiciones geográficas y vías de acceso, es decir el país requiere de infraestructura vial, interveredal, intermunicipal, entre ciudades, y ésta falla afecta a las comunidades más vulnerables, generando aislamiento poblacional. Corrupción, manejos irregulares con respecto a los recursos económicos de las entidades territoriales (Cortés, 2012).

Ahora bien, con respecto a los presupuestos de ausencia de Estado y Estado de Cosas Inconstitucional, existe una relación evidente, como se aprecia en la Tabla 1.

Los fines de la declaración del Estado de Cosas Inconstitucional consisten en introducir medidas de prevención, atención, promoción y estabilización para los ciudadanos, con el propósito de poder mantener el Estado de bienestar.

Tabla 1.

\begin{tabular}{|l|l|}
\hline \multicolumn{1}{|c|}{ Ausencia de Estado } & \multicolumn{1}{c|}{ Estado de Cosas Inconstitucional } \\
\hline $\begin{array}{l}\text { 1. Ineficiencia en la prestación de servicios } \\
\text { públicos }\end{array}$ & $\begin{array}{l}\text { 1. Vulneración masiva de los derechos } \\
\text { constitucionales }\end{array}$ \\
\hline $\begin{array}{l}\text { 2. Ineficacia, ineficiencia e insuficiencia de } \\
\text { políticas públicas e institucionales }\end{array}$ & $\begin{array}{l}\text { 2. Prolongada omisión de las autoridades en el } \\
\text { cumplimiento de sus obligaciones }\end{array}$ \\
\hline $\begin{array}{l}\text { 3. Pobreza, corrupción y ubicación } \\
\text { geográfica }\end{array}$ & $\begin{array}{l}\text { 3. La no expedición de medidas legislativas, } \\
\text { administrativas y presupuestales }\end{array}$ \\
\hline
\end{tabular}




\section{b. El poder discrecional de la Corte Constitucional en el Estado de Cosas Inconstitucional}

\section{Las políticas públicas}

Es forzoso aceptar que al momento de diseñar e implementar una determinada política pública de protección a la población desplazada, las autoridades competentes deben efectuar un ejercicio de ponderación establecimiento de áreas prioritarias. Es así que no puede el Estado satisfacer la dimensión prestacional de los derechos constitucionales de los desplazados, dadas las restricciones materiales y la dimensión del fenómeno de desplazamiento forzado.

Las políticas públicas consisten en "el conjunto de actividades de las instituciones de gobierno, actuando directamente o a través de agentes, y que van dirigidas a tener una influencia determinada sobre la vida de los ciudadanos" (Pallares, 1988, p. 13), es decir, que son actuaciones del gobierno para mantener el bienestar de la comunidad, y promover su desarrollo. Es claro que el Estado en ningún caso puede desconocer lesionar o amenazar el núcleo esencial de los derechos fundamentales de los desplazados.

Los instrumentos que utilizan los diversos Estados en materia de políticas públicas son: los servicios, los recursos financieros y las normas jurídicas. El primero se refiere a la necesidad de un determinado número de personas para la elaboración de las políticas públicas, es decir, personas capacitadas para estudiar las circunstancias que se presenten y poder establecer normas para solucionarlas. Los recursos financieros, que buscan proveer un mejor desarrollo e implantar políticas beneficiosas para la comunidad, y las normas jurídicas, que desempeñan un papel fundamental, pues mediante ellas se autorizan y ejecutan las diversas acciones proyectadas para satisfacer las necesidades de los habitantes.

\section{Las órdenes de la Corte Constitucional y el Estado de Cosas hoy}

La Corte Constitucional profiere decisiones de ejecución simple, dirigidas a disponer la abstención o la acción, que pueden o deben ser efectuadas por una autoridad sin el concurso de otra; y órdenes complejas que involucran a varias autoridades y requieren acciones coordinadas.

Con respecto al tema de la población desplazada, la Corte decide que la Red de Solidaridad Social y las Secretarías de Educación deben realizar acciones para el acceso efectivo a la salud, la alimentación y la educación. Igualmente, ordena que el Consejo Nacional para la Atención Integral a la Población Desplazada por la Violencia, adopte un programa de acción para corregir los errores en cuanto a la capacidad institucional, así como la realización de acciones destinadas a prevenir que los derechos de los ciudadanos en situación de desplazamiento sean vulnerados. En dicho fallo, la Corte estableció que la Red de Solidaridad Social debía realizar gestiones, dentro de un tiempo estipulado, para concretar la ayuda humanitaria solicitada por parte de los afectados.

La Corte Constitucional rompe el límite del marco de sus competencias constitucionales y legales, en la medida en que evalúa las circunstancias y problemas de los ciudadanos, elabora una solución y genera políticas 
públicas en sus decisiones, ya que planifica las actividades o estrategias de cada entidad encargada y determina las acciones a seguir por las mismas (Cortés, 2012).

Hoy el panorama no es alentador, hay más de 1.6 millones de desplazados en Colombia, la Misión de la Pobreza y la Desigualdad de Planeación Nacional, establece que la situación de los hogares víctimas del desplazamiento en los municipios receptores es más precaria que la que vive en los mismos lugares los pobres urbanos y los hogares indigentes. "Por una parte, el tamaño del hogar, el número de menores de edad y la tasa de dependencia son mayores para los hogares desplazados frente a los pobres urbanos y rurales. De igual forma los hogares desplazados presentan menores dotaciones de capital humano medidas a partir de los años de escolaridad, que los hogares pobres e indigentes" (Ibañez \& Moya, 2009, p. 12).

Los niveles de desempleo para los miembros de los hogares desplazados son mucho más altos que los que se tienen para los miembros de familias pobres urbanas y rurales así como para la población en estado de indigencia en las ciudades: "Para los menores de edad, las bajas tasas de asistencia educativa, los índices de deserción escolar y la presión para vincularse en actividades generadoras de ingresos a una temprana edad, comprometen la posibilidad de que los menores de edad puedan superar sus condiciones de vulnerabilidad en el futuro y se conviertan entonces en mecanismos de transmisión intergeneracional de la pobreza" (Ibáñez \& Moya, 2009 p. 45).

En materia de salud, se advierte sobre el alto grado de vulnerabilidad y precariedad en la que se encuentran los desplazados en Colombia. Señala que si bien hay más hogares afiliados al Sistema de Seguridad Social, la salud de la población desplazada se deteriora como consecuencia de la misma situación por la que atraviesan. La conclusión principal es clara: sin una intervención decidida de la sociedad, la población desplazada y sus futuras generaciones están condenadas a la pobreza.

Los principales problemas que impiden la eficacia de las leyes y las disposiciones constitucionales, tienen que ver con la infraestructura del Estado y sus responsabilidades, el Estado no cuenta con la infraestructura para la atención las víctimas, existe y existirá, representación política de fuerzas que fueron usurpadoras, que claramente intervienen en los procesos de atención y reparación, las víctimas conviven bajo una alto poder de intimidación, víctimas sin adecuada representación legal ni asesoría jurídica, todo ello aumenta su estado de vulnerabilidad, las víctimas no tienen claridad en la ley ni en los procesos, hay una falta de acompañamiento a las víctimas, el nivel de impunidad y la convivencia de víctimas con sus victimarios es el principal obstáculo para la superación de la crisis.

\section{REFERENCIAS BIBLIOGRÁFICAS}

Arango, R. (2004). Derecho, Constitucionalismo y Democracia. Bogotá: Ed. U. Externado.

Bernal, C. (2007). Democracia y Globalización en América Latina. En: El derecho en el contexto de la globalización. Editor Gonzalo Ramírez. Bogotá: Ed. U. Externado.

Calderón, J. (2008). Las políticas públicas en la encrucijada: políticas sociales y competitividad 
sistémica. Enciclopedia Virtual. Disponible en: [http://ctinobar.webs.ull.es/1docencia/ DESIGUALDAD\%20SOCIAL/CALDERON. pdf].

Cepeda, M. (1993). Introducción a la Constitución de 1991. Hacia un nuevo constitucionalismo. Colombia: Ed. Imprenta Nacional de Colombia.

Cortés Zambrano, S. (2008). Ausencia de estado, hecho que legitima a la Corte Constitucional a fallar fuera de su competencia. Trabajo de grado. Bogotá: USTA.

Cortés Zambrano, S. (2012). Poder Discrecional de la Corte Constitucional en el Estado de Cosas Inconstitucional. En revista via in veniendi et iudicandi. Vol. 7 No 2. USTA.

Favoreau, F. et al. (1984). Tribunales Constitucionales y derechos Fundamentales. Madrid: Centro de Estudios Constitucionales.

Ferrajoli, L. (2003). Pasado y futuro del Estado de Derecho. En Neoconstitucionalismos, editor Miguel Carbonell. Madrid: Ed. Trotta.

Fioravanti, M, (1996). Los derechos fundamentales. Madrid: Ed. Trotta.

García Pelayo, M. (1991). Estado Legal y Estado Constitucional de Derecho. Madrid: Centro de Estudios Constitucionales.

Aragón, M. (1997). El Juez Ordinario entre Legalidad y Constitucionalidad. Colombia: Ed. U. Externado.

Bernal, C. (2005). El Derecho de los Derechos. Bogotá: Ed. Universidad Externado de Colombia.

Bernal, C. (2007). El Neoconstitucionalismo a Debate. Instituto de estudios constitucio- nales. Bogotá: Ed. Universidad Externado de Colombia.

Comanducci, P. (2003). Formas de (Neo) constitucionalismo. Un análisis metateórico. Edición de Miguel Carbonell. Madrid: Editorial Trotta.

Ferrajoli, L. (2003). Pasado y Futuro del Estado de Derecho. Ed. de Miguel Carbonell. Madrid: Editorial Trotta.

García Figueroa, J. (1996). Principios y Positivismo Jurídico. El no positivismo principialista en la teorías de de Dworkin y Alexy. Madrid: Centro de Estudios Políticos y Constitucionales.

García Figueroa, J. (2003), Teoría del derecho en tiempos de constitucionalismo. Edición de Miguel Carbonell. Editorial Trotta.

Guastini, R. (2003). La "constitucionalización" del ordenamiento jurídico: el caso italiano. Edición de Miguel Carbonell. Madrid: Editorial Trotta.

Ibañez, A. (2009). El desplazamiento forzoso en Colombia: un camino sin retorno hacia la pobreza. Bogotá: Ed. Unidades.

López, D. (2000). El derecho de los jueces. Bogotá: Ed. Uniandes.

Morelli, S. (1997). La Corte Constitucional ¿Un Legislador Complementario? Bogotá: Ed. U Externado.

Moreso, J. J. (2003). "Comanducci sobre Neoconstitucionalismo". Trabajo presentado como una réplica a la contribución de Paolo Comanducci al Seminario Albert Calsamiglia, que tuvo lugar en la Universidad de Pompeu Fabra (Barcelona). 
ONU (2014). Programa Mundial de Alimentos. Informe: Vulnerabilidad a la seguridad alimentaria a la población desplazada por violencia. Colombia.

Schmitt C. (1983). La defensa de la Constitución, Madrid: Tecnos.

Savigny, F. (2004). Metodología jurídica, Buenos Aires: Valletta.
Uprimny, R. (2004). Abierta pero no neutra, Constitución y modelo económico en Colombia. En: Memorias del conservatorio 'Diálogo entre abogados y economistas sobre la Constitución en el aspecto económico', Bogotá: Ministerio de Hacienda y Crédito Público.

Zagrebelsky, G. (2002). El Derecho Dúctil. Ley Derechos y Justicia. Madrid: Editorial Trotta. 